The Mechanism of Phase Transformation in Metals A Symposium organized by the Institute of Metals and held at the Royal Institution, London, on 9 November 1955. (Institute of Metals Monograph and Report Series, No. 18.) Pp. iv $+346+45$ plates. (London: The Institute of Metals, 1956.) 50s.; 7.50 dollars.

DEAILS of the phase equilibria occurring in alloys represent a major foundation metal theory. The more difficult task is not so much to determine the actual phase conditions at equilibrium, but rather the mechanism of transformation from one set of conditions to another. In particular, it is the formation of various metastable products, en route to equilibrium or under conditions that do not allow the normal path to be followed, that provides such a diverse field of behaviour for investigation.

The present monograph is valuable because it gives in one volume a satisfactory summary of know. ledge to date, which should prove useful not only to those with specific interest in the mechanism of phase transformations, but also for those who merely wish to keep up to date in a general way. The treatment has been classified broadly under two headings: first, those changes following a nucleation and growth sequence; and secondly, martensitic transformations involving, in contrast, a co-operative movement of the atoms. In each case a lengthy general review is followed by a number of shorter and more specific papers. Finally, there are more than sixty pages of general discussion. The matter is of high standard and forms a sound and stimulating account.

A. R. BaIleY

\section{Records and Research in Engineering and Industrial} Science

By Dr. J. Edwin Holmstrom. Third edition, rewritten and enlarged. Pp. xii +491 . (London : Chapman and Hall, Ltd., 1956.) 60s. net.

TNCHANGED in title and in theme, the third edition of Dr. Holmstrom's book has been so substantially enlarged, re-arranged and re-written that it could reasonably be described as a new book. One chapter, dealing with the technician as a person, has been discarded, but neither in title nor in content are the nine that remain, apart possibly from the first, at all comparable with those in the second edition. The first chapter, in which Dr. Holmstrom discusses the nature and methods of technical science, illustrates one of the features in which the third edition constitutes a marked improvement on the earlier editions. It is characterized by a representative selection of references to outstanding postwar writings on this theme, and some thirty of the hundred odd additional pages of the new edition are occupied by an excellent bibliography. Dr. Holmstrom's reading is encyclopædic, but although he makes no claim to comprehensiveness, the basis of his selections either in time or in extent is not obvious and may be misleading to a reader. It is puzzling to find, for example, the "Dictionary of Applied Physics" and Kirk and Othman's "Encyclopedia of Chemical Technology" included, but not the "Dictionary of Applied Chemistry". Again, his references to organizations in the United States are strikingly incomplete in respect of publications of the past year or so, within which period he has given other references that might well have been too late to be included. There are also some surprising omissions in his account of organizations in other countries-for example, the National Foundation for Scientific Research, Brussels, and the Institute for Scientific Research in Central Africa. The book has been so greatly improved both bibliographically and in treatment of post-war developments that it would be a pity if readers were led to attribute to it a comprehensiveness to which the author himself makes no pretence.

\section{R. Brightman}

\section{Realities of Space Travel}

Selected Papers of the British Interplanetary Society. Edited by L. J. Carter. Pp. $431+23$ plates. (London : Putnam and Co., Ltd., 1957.) 35s. net. $A$ S part of its activities, the British Interplanetary relating to space-travel. A number of those which have appeared since 1948 have been collected in a single volume under the editorship of the secretary of the Society. The compilation forms an excellent introduction to various aspects of extra-terrestrial flight which should be understandable to anybody with some knowledge of elementary mathematics and physies.

Escape from the Earth's gravitational field, the dynamics of propulsion and certain aspects of orbit theory are fully treated. The problem of navigation is regrettably ignored.

Detailed designs of vehicles which might be used are rightly not presented. Attention is instead confined to basic features, such as rocket motors and wings for braking in descending through an atmosphere. The concentration on the question of what is possible in principle is to be commended. However, it might have been desirable to consider the extent of the practical engineering difficulties that would be encountered in the assembly of the satellite stations proposed by von Pirquet, in landing on and taking off from the Moon, or in one of the other major projects envisaged.

The survey is completed by interesting contributions on the following: instrumented satellites; meteor and cosmic ray hazards ; physiological effects ; air, water and food supplies for a voyage ; conditions on neighbouring worlds.

There are numerous informative figures and tables and the general production is of a high standard.

D. R. Bates

Introduction to Structure in Organic Chemistry By Prof. C. K. Ingold. Pp. vii +200. (London: G. Bell and Sons, Ltd., 1956.) 20s. net.

THE present volume consists of the first four chapters of Prof. Ingold's larger work, "Structure and Mechanism in Organic Chemistry" (1953). Dr. W. A. Waters, in a highly commendatory review of this earlier book (Nature, 173, 278; 1954), called it a "classic of scholarship". Chapter 1 deals with covalency, its physical interpretation and electronic character, and with the interpretation of stereochemical form; Chapter 2 with interactions between non-reacting molecules, and also with intramolecular interaction, its significance and its internal transmission; Chapter 3 with electric dipole moments, and with the physical properties of molecules; Chapter 4 with the theory of aromatic character, and with the diamagnetic and other physical properties of the aromatic nucleus. The book is therefore essentially an exposition of the general principles of molecular structure with all the illustrations taken from organic chemistry.
G. Fowres 